\title{
Minimum alcohol pricing: a shameful episode
}

The third sentence in the second paragraph of this Editor's Choice (BMJ 2014;348:g110, doi:10.1136/bmj.g110) should have read that "the government had the necessary evidence, in the form of a report delivered to the Home Office five months earlier." The published sentence incorrectly states that "the government had the necessary evidence, in the form of a report commissioned by the government in 2008," which wrongly suggests that Sheffield University agreed to delay for five years the publication of a report that undermined the government's reason for abandoning the policy of minimum pricing. In fact, as the $B M J$ has made clear elsewhere, Sheffield University "informally agreed" to delay publication of the report for five months, releasing it only when the U-turn had been announced.

Cite this as: BMJ 2014;348:g134

๑ BMJ Publishing Group Ltd 2014 